\title{
World's soils are under threat
}

Luca Montanarella $^{1}$, Daniel Jon Pennock ${ }^{2}$, Neil McKenzie ${ }^{3}$, Mohamed Badraoui ${ }^{4}$, Victor Chude ${ }^{5}$, Isaurinda Baptista $^{6}$, Tekalign Mamo ${ }^{7}$, Martin Yemefack ${ }^{8}$, Mikha Singh Aulakh ${ }^{9}$, Kazuyuki Yagi $^{10}$, Suk Young Hong ${ }^{11}$, Pisoot Vijarnsorn ${ }^{12}$, Gan-Lin Zhang ${ }^{13}$, Dominique Arrouays ${ }^{14}$, Helaina Black ${ }^{15}$, Pavel Krasilnikov ${ }^{16}$, Jaroslava Sobocká ${ }^{17}$, Julio Alegre ${ }^{18}$, Carlos Roberto Henriquez $^{19}$, Maria de Lourdes Mendonça-Santos ${ }^{20}$, Miguel Taboada ${ }^{21}$, David Espinosa-Victoria ${ }^{22}$, Abdullah AlShankiti ${ }^{23}$, Sayed Kazem AlaviPanah ${ }^{24}$, Elsiddig Ahmed El Mustafa Elsheikh ${ }^{25}$, Jon Hempel ${ }^{26}$, Marta Camps Arbestain $^{27}$, Freddy Nachtergaele ${ }^{28}$, and Ronald Vargas ${ }^{28}$

${ }^{1}$ European Commission - DG JRC, Via E. Fermi, 2749, 21027 Ispra (VA), Italy

${ }^{2}$ College of Agriculture and Bioresources, University of Saskatchewan, 51 Campus Drive, Saskatoon SK S7N 5A8, Canada

${ }^{3}$ CSIRO Agriculture Flagship, B.E. Butler Laboratory, GPO Box 1666, Canberra, ACT 2601, Canberra, Australia

${ }^{4}$ INRA, Rabat, Morocco

${ }^{5}$ National Programme for Food Security, 127 Adetokunbo Ademola Crescent, Wuse 2, Abuja, Nigeria

${ }^{6}$ Instituto Nacional de Investigação e Desenvolvimento Agrário (INIDA) - São Jorge dos Órgãos CP 84, Praia, Cabo Verde

${ }^{7}$ Ministry of Agriculture, P.O. Box 62347, Addis Ababa, Ethiopia

${ }^{8}$ International Institute of Tropical Agriculture (IITA) and Institute of Agricultural Research for Development (IRAD), Yaoundé, Cameroon

${ }^{9}$ Banda University of Agriculture \& Technology, Banda, 210001, Uttar Pradesh, India

${ }^{10}$ National Institute for Agro-Environmental Sciences (NIAES), 3-1-3 Kannondai, Tsukuba 305-8604, Japan

${ }^{11}$ National Academy of Agricultural Science (NAAS), Rural Development Administration (RDA), Wanju-gun, Jeonbuk, South Korea

${ }^{12}$ Chaipattana Foundation, Bangkok, Thailand

${ }^{13}$ State Key Laboratory of Soil and Sustainable Agriculture, Institute of Soil Science, Chinese Academy of Sciences, Nanjing 210008, China

${ }^{14}$ INRA, InfoSol Unit, US 1106, 45075, Orléans, France

${ }^{15}$ Ecological Sciences Group, The James Hutton Institute, Craigiebuckler, Aberdeen AB15 8QH, Scotland, UK

${ }^{16}$ Eurasian Center for Food Security, Lomonosov Moscow State University, Moscow, Russia

${ }^{17}$ National Agricultural and Food Centre - Soil Science and Conservation Research Institute, Bratislava, Slovakia

${ }^{18}$ Departamento de Suelos, National Agrarian University, La Molina, Peru

${ }^{19}$ Centro de Investigaciones Agronómicas, Facultad de Ciencias Agroalimentarias, Universidad de Costa Rica, San Pedro, Costa Rica

${ }^{20}$ EMBRAPA - Brazilian Agricultural Research Corporation/The National Centre of Soil Research (Embrapa Solos), Rua Jardim Botânico, 1024, Rio de Janeiro, RJ, Brazil

${ }^{21}$ Instituto de Suelos and CONICET, CIRN, INTA, Nicolás Repetto y De los Reseros S/N, CP 1686 Hurlingham, Buenos Aires, Argentina

${ }^{22}$ Colegio de Postgraduados, Mexico City, Mexico

${ }^{23}$ International Center for Biosaline Agriculture (ICBA), Dubai, United Arab Emirates

${ }^{24}$ Department of Remote Sensing and GIS, University of Tehran, Tehran, Iran

${ }^{25}$ Department of Soil \& Environment Sciences, University of Khartoum, Khartoum, Republic of the Sudan

${ }^{26}$ USDA-NRCS National Soil Survey Center,100 Centennial Mall, Lincoln, NE 68508, USA

${ }^{27}$ Institute of Agriculture and Environment, Massey Agriculture, Palmerston North 4442, New Zealand 


\author{
${ }^{28}$ Food and Agriculture Organization of the United Nations (FAO), Rome, Italy \\ Correspondence to: Luca Montanarella (luca.montanarella@jrc.ec.europa.eu)
}

Received: 28 October 2015 - Published in SOIL Discuss.: 9 December 2015

Accepted: 24 February 2016 - Published: 29 February 2016

\begin{abstract}
The Intergovernmental Technical Panel on Soils has completed the first State of the World's Soil Resources Report. Globally soil erosion was identified as the gravest threat, leading to deteriorating water quality in developed regions and to lowering of crop yields in many developing regions. We need to increase nitrogen and phosphorus fertilizer use in infertile tropical and semi-tropical soils - the regions where the most food insecurity among us are found - while reducing global use of these products overall. Stores of soil organic carbon are critical in the global carbon balance, and national governments must set specific targets to stabilize or ideally increase soil organic carbon stores. Finally the quality of soil information available for policy formulation must be improved - the regional assessments in the State of the World's Soil Resources Report frequently base their evaluations on studies from the 1990s based on observations made in the 1980s or earlier.
\end{abstract}

\section{Introduction}

Soils are fundamental to life on Earth. They are central to sustainable development and the future we want. Soils have critical relevance to global issues such as food and water security and climate regulation (Koch et al., 2013; Lal, 2004; McBratney et al., 2014), and they are increasingly recognized as major contributors to a wide range of ecosystem services (Dominati et al., 2010). However, until now, no global statement on the world's soils resources has been released. Soil resources have been seen as a second-tier priority; until 2013 no international governance body had existed that advocated for and coordinated initiatives to ensure that knowledge and recognition of soils are appropriately represented in globalchange dialogues and decision-making processes.

The societal responses required to achieve sustainable soil management are complex and multi-faceted (Arnold et al., 1990). The implementation of soil management decisions is typically made locally and occurs within widely differing socio-economic contexts. The development of specific measures appropriate for adoption by local decision-makers requires multi-level, interdisciplinary initiatives by many stakeholders - partnerships are therefore essential. In recognition of this, the Global Soil Partnership (GSP) (http://www. fao.org/globalsoilpartnership) was established by members of the Food and Agriculture Organization of the United Nations (FAO). Its Intergovernmental Technical Panel on Soils (ITPS) was established at the first Plenary Assembly of the GSP in June 2013. After two years of work, the ITPS is publishing the first-ever comprehensive State of the World's Soil Resources Report (SWSR) (ITPS, 2015). In this paper we summarize the main outputs of this report and stress what should be the main priorities at the global level.

\section{State of the World's Soil Resources - the why and how}

The ITPS is composed of 27 soil experts nominated by the FAO members and representing all the regions of the world. The main function of the ITPS is to provide scientific and technical advice and guidance on global soil issues to the GSP primarily and to specific requests submitted by global or regional institutions. One of its main tasks for 2013-2015 has been production of the SWSR. The goal of the SWSR is to make clear the essential connections between human wellbeing and the soil. The report provides a benchmark against which the world's collective progress to conserve this essential resource can be measured.

About 200 soil scientists from 60 countries contributed directly to the report. Their assessment has synthesized the scientific knowledge embodied in more than 2000 peerreviewed scientific publications. The report provides a global perspective on the current state of the soil, its role in providing ecosystem services, and the threats to its continued contribution to these services. The specific threats to soil function considered in the report are erosion, compaction, acidification, contamination, sealing, salinization, waterlogging, nutrient imbalance (i.e., both nutrient deficiency and nutrient excess), and losses of soil organic carbon and of biodiversity. Several threats (e.g., waterlogging, salinization) have both natural and human-induced causes; our focus was on human-induced changes to the state and trend of the threats.

\section{What are the global drivers of soil change?}

The primary global drivers of soil change are population growth and economic growth. While economic growth may eventually be decoupled from increases in consumption of resources and generation of waste, it will continue to be a strong driver of soil change for the next few decades at least. 

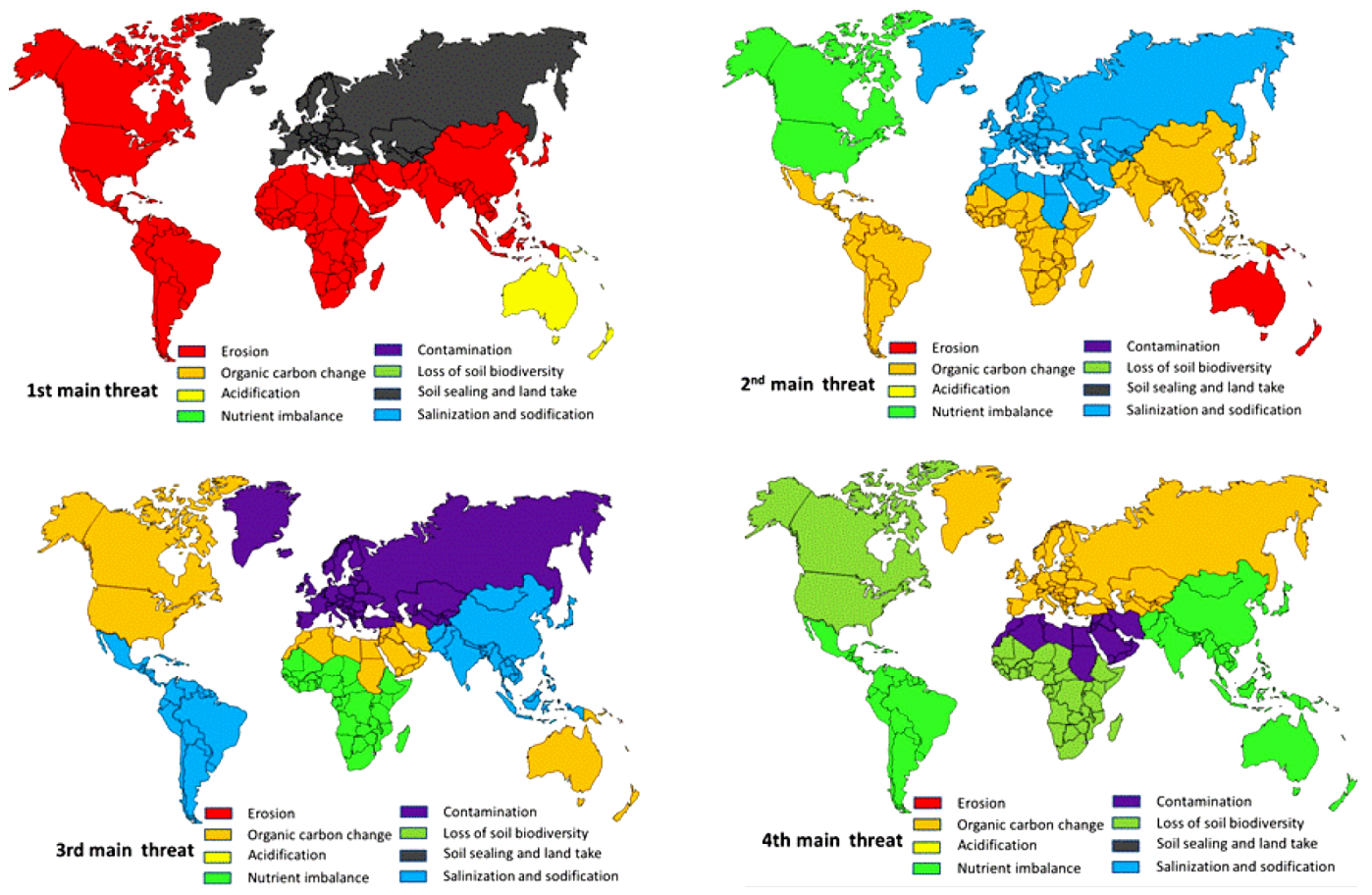

Figure 1. Global assessment of the four main threats to soil by FAO regions.

The 20th century has witnessed extraordinary population and economic growth and an associated revolution in agriculture. The world population of 7.2 billion in mid-2013 is projected to increase by almost 1 billion people within the next 12 years. It is expected to reach 9.6 billion in 2050 and 10.9 billion in 2100. Most of this growth will occur in low-income countries. Many of these countries (e.g., in West Africa) have infertile soils and low levels of agricultural productivity. Factors such as education, cultural values, civil strife, the effectiveness of markets, and the wealth or poverty of the land users are also important drivers of global soil change.

Climate change is the third primary driver of soil change through its current and anticipated effects on land use and management. The impact of climate change on soil functioning is the largest source of uncertainty in any projections of the trends in key ecosystem services provided by the soil. Climate change will have significant impacts on soil resources. For instance, the change in water availability due to changes of quantity and pattern of precipitation and higher temperatures entailing a higher evaporative demand will influence the rate of actual evaporation, groundwater recharge, and the generation of runoff according to local conditions. Warminginduced changes in soil temperature and moisture regimes may increase the soil organic carbon (SOC) decomposition rate and intensify the risks of erosion and desertification.

\section{What are the main threats to soil functions?}

While there is cause for optimism in some regions, the overwhelming conclusion from the report is that the majority of the world's soil resources are in only fair, poor, or very poor condition. The most significant threats to soil function at the global scale are soil erosion, loss of soil organic carbon, and nutrient imbalance (Fig. 1).

The current outlook is for the situation to worsen - unless concerted actions are taken by individuals, the private sector, governments, and international organizations.

The global assessment should not mask large regional differences in soil threats. For instance, soil erosion is seen as a major priority in sub-Saharan African countries while soil sealing is considered the major soil threat in western Europe.

\section{The way forward}

The assessment contained in the first report on the status of the world's soil resources is long overdue. The singular focus on soil has a simple yet profound basis. Managed well, soil circulates chemical elements, water, and energy for great human benefit. If soil is managed poorly, it is impossible to be optimistic about the future (Richter and Markewitz, 2001; Admunson et al., 2015). The current trajectories in soil condition have potentially catastrophic consequences that will affect millions of people in some of the most vulnerable regions over coming decades. More importantly, the global community is presently ill-prepared and ill-equipped 
to mount a proportionate response. Countries can change current trajectories. The starting point is implementation of the actions outlined in the World Soil Charter (Food and Agriculture Organization, 2015) that has been endorsed by the FAO countries in direct connection with the plans of action of the Global Soil Partnership.

Overall we believe the following four actions are the greatest priorities:

1. Sustainable soil management can increase the supply of healthy food for the most food-insecure regions. Specifically we should minimize further degradation of soils and restore the productivity of soils that are already degraded in those regions where people are most vulnerable.

2. The global stores of soil organic matter (i.e., soil organic carbon (SOC) and soil organisms) should be stabilized or increased. Each nation should identify locally appropriate SOC-improving management practices and facilitate their implementation. They should also work towards a national-level goal of achieving a stable or positive net SOC balance.

3. Compelling evidence exists that humanity is close to the global limits for total fixation of nitrogen and regional limits for phosphorus use. Therefore we should act to stabilize or reduce global $\mathrm{N}$ and $\mathrm{P}$ fertilizer use while simultaneously increasing fertilizer use in regions of nutrient deficiency. Increasing the efficiency of $\mathrm{N}$ and $\mathrm{P}$ use by plants is a key requirement to achieve this goal.

4. The regional assessments in the State of the World's Soil Resources Report frequently base their evaluations on studies from the 1990s based on observations made in the 1980 s or earlier. The lack of current data causes significant uncertainty in our assessments of soil threats at the regional scale. We must improve our knowledge about the current state and trend of the soil condition. An initial emphasis should be on improving observation systems to monitor our progress in achieving the three priorities outlined above.

As a next step, the ITPS is drafting Voluntary Guidelines on Sustainable Soil Management that will begin to bridge the gap between the local decision-making required for implementation of sustainable soil management and the highlevel governance work of the GSP. The International Year of Soils in 2015 will be remembered in the coming decades as the year when the soil challenge confronting the world was clearly articulated. History will record whether this generation of decision makers responded with sufficient zeal to ensure that soil did indeed remain as humanity's silent ally.
Acknowledgements. The State of the World's Soil Resources Report was possible thanks to the support of the Food and Agriculture Organization of the UN, the Global Soil partnership Secretariat, and the financial contribution of the European Commission.

Edited by: A. Don

\section{References}

Admunson, R. L., Berhe, A. A., Hopmans, J. W., Olson, C., Sztein, A. E., and Sparks, D. L.: Soil and Human Security in the 21st Century, Science, 348, 6235, 647, doi:10.1126/science.1261071, 2015.

Arnold, R. W., Szabolcs, I., and Targulian, V. O.: Global soil change. Report of an IIASA-ISSS-UNEP task force on the role of soil in global change. International Institute for Applied Systems Analysis, Laxenburg, 1990.

Dominati, E., Patterson, M., and Mackay, A.: A framework for classifying and quantifying the natural capital and ecosystem services of soils, Ecol. Econ., 69, 1858-1868, 2010.

Food and Agriculture Organization: Revised World Soil Charter, http://www.fao.org/fileadmin/user_upload/GSP/docs/ITPS_ Pillars/annexVII_WSC.pdf (last access: 29 February 2016), 2015.

Global Soil Partnership: www.fao.org/globalsoilpartnership (last access: 29 February 2016), 2015.

ITPS: Intergovernmental Technical Panel on Soil: State of the World's Soil Resources report, FAO Publication, 2015.

Koch, A., Field, D., McBratney, A. B., Adams, M., Hill, R., Crawford, J., Minasny, B., Lal, R., Abbott, L., O’Donnel, A., Angers, D., Baldock, J., Barbier, E., Binkley, D., Parton, W., Wall, D. H., Bird, M., Chenu, C., Flora, C. B., Goulding, K., Grunwald, S., Hempel, J., Jastrow, J., Lehmann, J., Lorenz, K., Morgan, C. L., Whitehead, D., Young, I., and Zimmermann, M.: Soil security: solving the global soil crisis, Global Policy, 4, 434-441, 2013.

Lal, R.: Soil Carbon Sequestration Impacts on Global Climate Change and Food Security, Science, 304, 1623-1627, 2004.

McBratney, A. B., Field, D. J., and Koch, A.: The dimensions of soil security, Geoderma, 213, 203-213, 2014.

Richter, D. D. and Markewitz, D.: Understanding soil change, Cambridge University Press, Cambridge, UK, 2001.

United Nations, Department of Economic and Social Affairs, Population Division, World Urbanization Prospects: The 2014 Revision, Highlights (ST/ESA/SER.A/352), 2014. 